BUDGETING : Journal of Business, Management and Accounting

Volume 2, Nomor 1, Desember 2020

e-ISSN: 2715-2480

p-ISSN: 2715-1913

DOI : https://doi.org/10.31539/budgeting.v2i1.1760

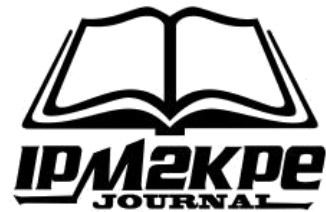

\title{
TURNOVER INTENTION BERDASARKAN RETENSI KARYAWAN DAN INSENTIF
}

\author{
Widya Nindi Pratiwi $^{1}$, Kokom Komariah ${ }^{2}$, Dicky Jhoansyah ${ }^{3}$ \\ Universitas Muhammadiyah Sukabumi ${ }^{1,2,3}$ \\ Widyanindipratiwiokto24@gmail.com ${ }^{1}$
}

\begin{abstract}
ABSTRAK
Tujuan penelitian ini adalah untuk mengetahui pengaruh retensi karyawan dan insentif dalam meningkatkan turnover intention pada PT. Star Comgistic Indonesia Kabupaten Sukabumi. Metode yang digunakan pada penelitian ini adalah kuantitatif dengan analisis secara deskriptif dan asosiatif. Sampel dipilih berdasarkan probabilitas sampling yang termasuk kedalam simple random sampling. Hasil penelitian menunjukkan bahwa nilai yang diperoleh dari analisis koefisien korelasi ganda adalah sebesar 0, 455 dengan pengaruh retensi karyawan dan insentif terhadap turnover intention adalah sebesar $18,0 \%$ serta sisanya $82 \%$ dipengaruhi oleh faktor- faktor lain diluar penelitian ini. Hasil uji $\mathrm{F}$ yang dilakukan memperoleh nilai Sig. 0,000 < 0,05; nilai $\mathrm{F}_{\text {hitung }} 10,741>\mathrm{F}$ tabel 2,36 . Simpulan, terjadi hubungan yang sedang antara retensi karyawan dan insentif dengan turnover intention. Retensi karyawan dan insentif berpengaruh positif dan signifikan terhadap turnover intention. Hal ini menunjukkan bahwa retensi karyawan dan insentif merupakan faktor yang membentuk turnover intention pada PT. Star Comgistic Indonesia Kabupaten Sukabumi.
\end{abstract}

Kata Kunci: Insentif, Retensi Karyawan, Turnover Intention

\begin{abstract}
The purpose of this study was to determine the effect of employee retention and incentives in increasing turnover intention at PT. Star Comgistic Indonesia, Sukabumi Regency. The method used in this research is quantitative with descriptive and associative analysis. The sample is selected based on probability sampling which is included in simple random sampling. The results showed that the value obtained from the multiple correlation coefficient analysis was 0.455 with the effect of employee retention and incentives on turnover intention was $18.0 \%$ and the remaining $82 \%$ was influenced by other factors outside of this study. The results of the $F$ test performed obtained the Sig value. $0.000<0.05$; F value count $10.741>$ F table 2.36. In conclusion, there is a moderate relationship between employee retention and incentives and turnover intention. Employee Retention and Incentives have a positive and significant effect on turnover intention. This shows that employee retention and incentives are factors that shape turnover intention at PT. Star Comgistic Indonesia, Sukabumi Regency.
\end{abstract}

Keywords: Employee Retention, Incentives, Turnover Intention 


\section{PENDAHULUAN}

Keberhasilan perusahaan sangat tergantung pada kualitas tenaga kerja yang dimilikinya. Oleh karena itu, Manajemen Sumber Daya Manusia (MSDM) harus mengelola, membangun dan memotivasi SDM yang dimiliki perusahaan secara optimal untuk meningkatkan efektifitas investasi mereka. Hal ini membuat perusahaan harus berupaya untuk memelihara dan menciptakan lingkungan kerja yang memadai dan senyaman mungkin agar dapat mendorong para karyawan untuk tetap bertahan bekerja.

Skill atau kemampuan karyawan sangat penting bagi perusahaan untuk mendukung keberhasilan perusahaan tersebut. Hal ini membuat pemimpin perusahaan perlu merekrut, melatih dan mempertahankan karyawan yang berkualitas. Dalam bekerja, karyawan dituntut untuk memberikan yang terbaik bagi perusahaan, sehingga harapan perusahaan terhadap karyawan dapat terpenuhi. Oleh karena itu, dibutuhkan kerja sama yang baik antara satu sama lainnya.

Seiring dengan meningkatnya persaingan pasar saat ini, membuat perusahaan atau organisasi harus memperkerjakan karyawan yang kompeten agar dapat memenangkan persaingan pasar. Mencari karyawan yang berbakat akan menghabiskan waktu dan uang bagi perusahaan, maka dari itu mempertahankan karyawan juga penting bagi perusahaan. Tingginya turnover karyawan membuat perusahaan menghabiskan tenaga dan sumber daya pada rekrutmen ulang. Para tim HRD tentunya mengetahui bahwa betapa proses rekrutmen hingga training baru itu cukup melelahkan.

Pemeliharaan karyawan atau retensi karyawan (employee retention) merupakan kemampuan perusahaan untuk mempertahankan karyawan potensial yang dimiliki perusahaan untuk tetap loyal terhadap perusahaan. Namun secara umum, hubungan antara employee retention terhadap kinerja bisa kompleks. Terbukti bahwa kinerja dapat menurun jika employee retention karyawan menurun dan ada kemungkinan akan terdapat stagnasi karyawan jika turnover terlalu rendah (Mathis \& Jackson, 2006).

Keinginan untuk pindah (turnover intention) merupakan pergerakan masuk dan keluarnya karyawan dalam suatu organisasi, kecenderungan atau niat karyawan untuk berhenti dari pekerjaan dan terjadi atas kemauannya sendiri atau diberhentikan dari perusahaan. Namun fenomena berpindah-pindah kerja bisa membawa dampak yang kurang baik bagi karyawan yang pindah kerja maupun yang menetap. Jika tingkat 
turnover tinggi, maka itu bisa mendorong atau memotivasi karyawan yang ada untuk tetap tinggal (Mobley, 2002).

Salah satu upaya perusahaan untuk mengurangi turnover karyawan adalah dengan memberikan motivasi berupa pemberian insentif kepada para karyawan sebagai bentuk apresiasi terhadap hasil kerja karyawan tersebut. Insentif merupakan pemberian uang di luar gaji yang dilakukan oleh pihak pemimpin organisasi sebagai pengakuan terhadap prestasi kerja dan kontibusi karyawan kepada organisasi (Mangkunegara, 2008).

Berdasarkan hasil pengamatan, peneliti menemukan bahwa PT. Star Comgistic Indonesia memiliki pemasalahan pada turnover intention yang membuat banyak karyawan berkeinginan untuk keluar. Hal ini dapat dilihat pada tabel berikut:

Tabel 1.

Data Jumlah Karyawan

PT. Star Comgistic Indonesia

\begin{tabular}{cccc}
\hline Bulan & Total Karyawan & Karyawan Keluar & Karyawan yang Masih Ada \\
\hline Mei & 882 & 4 & 878 \\
Juni & 878 & 18 & 860 \\
Juli & 860 & 13 & 847 \\
\hline
\end{tabular}

(Sumber: PT. Star Comgistic Indonesia, 2018)

Permasalahan tersebut diduga disebabkan karena hubungan karyawan yang kurang baik dan juga karena perusahaan tidak memberikan penghargaan berupa insentif terhadap karyawannya yang sudah bekerja dengan terampil. Berdasarkan uraian latar belakang masalah di atas, maka dapat dikatakan bahwa turnover intention pada kinerja karyawan PT. Star Comgistic Indonesia belum stabil dan meningkat.

\section{KAJIAN TEORI}

\section{Retensi Karyawan}

Keberhasilan suatu perusahaan sangat dipengaruhi oleh sumber daya manusia yang berada diperusahaan tersebut, karena sumber daya manusia yang mengatur jalannya perusahaan. Manajemen sumber daya manusia merupakan perancangan sistem formal dari suatu organisasi yang digunakan untuk memastikan keefektifan dan keefisienan dari kemampuan karyawan dalam memenuhi tujuan organisasi (Mathis \& Jackson, 2006). 
Kehadiran para karyawan di dalam perusahaan sangat penting karena di dalam perusahaan terdapat visi dan misi perusahaan. Oleh karena itu, perusahaan harus memikirkan cara untuk mempertahankan para karyawan yang efektif dan efisien agar karyawan tetap berkerja dan bertahan pada perusahaan. Retensi karyawan adalah seberapa banyak karyawan sebuah perusahaan tetap berada di perusahaan tersebut dalam jangka waktu tertentu. Jika ingin memaksimalkan retensi, seharusnya perusahaan harus memaksimalkan jumlah karyawan yang tetap dalam perusahaan karena memang karyawan tersebut ingin tetap dalam perusahaan, bukan karena paksaan dari perusahaan. Retensi juga terkait dengan meminimalisasi karyawan yang berkinerja rendah untuk meningkatkan ruang lapang dan sumber daya bagi karyawan yang kinerja dengan baik (Carsen, 2005).

Upaya untuk mempertahankan tidaklah mudah, karena sudah menjadi persoalan utama dalam setiap organisasi dan banyak juga faktor lain yang menjadi alasannya. Menurut Mathis \& Jackson (2006) umumnya ada 5 dimensi pada retensi karyawan yaitu, sebagai berikut: 1) komponen organisasi, beberapa komponen organisasional dapat mempengaruhi karyawan dalam memutuskan apakah bertahan atau meninggalkan perusahaan. Perusahaan yang memiliki budaya dan nilai yang positif dan berbeda mengalami perputaran karyawan yang lebih rendah; 2) peluang karir organisasi, survei terhadap karyawan di dalam semua jenis pekerjaan tetap menunjukan bahwa usaha pengembangan karir organisasional dapat mempengaruhi tingkat retensi karyawan secara signifikan.

Selanjutnya, 3) penghargaan, penghargaan nyata yang diterima oleh karyawan karena kinerjanya dapat berupa gaji, insentif dan tunjangan. Banyak survei dan pengalaman para professional SDM menunjukan bahwa satu hal yang penting terhadap retensi karyawan adalah mempunyai praktik kompensasi kompetitif. Banyak manajer yakin bahwa uang merupakan faktor retensi karyawan yang utama; 4) rancangan tugas dan pekerjaan, faktor mendasar yang mempengaruhi retensi karyawan adalah sifat dari tugas dan pekerjaan yang dilakukan. Pertama, retensi karyawan dipengaruhi oleh proses seleksi. Beberapa organisasi menemukan bahwa angka perputaran karyawan yang tinggi dalam beberapa bulan lamanya pekerjaan sering kali dihubungkan dengan usaha penyaringan seleksi yang kurang memadai; 5) hubungan karyawan, faktor terakhir yang 
dapat mempengaruhi retensi karyawan didasarkan pada hubungan yang dimiliki para karyawan dalam organisasi.

\section{Insentif}

Insentif adalah tambahan balas jasa yang diberikan kepada karyawan tertentu yang prestasinya di atas pretasi standar (Hasibuan, 2011). Insentif dapat meningkatkan motivasi karyawan dalam upaya mecapai tujuan-tujuan organisasi (Mangkunegara, 2009). Insentif merupakan penghargaan atau ganjaran positif yang diberikan oleh perusahaan untuk memotivasi para pekerja agar produkivitas kerjanya tinggi, sifatnya tidak tetap atau sewaktu-waktu (Nawawi, 2008).

Insentif pada dasarnya mencakup sikap mental yang akan mendorong seseorang untuk tidak cepat merasa puas, akan tetapi harus mengembangkan diri dan meningkatkan kemampuan kerja dengan cara selalu memperbaiki dan mengupayakan peningkatan. Adapun dimensi dari insentif menurut Rivai (2009) yaitu sebagai berikut: 1) kebutuhan, cara ini menunjukkan bahwa insentif pada karyawan didasarkan pada tingkat urgensi kebutuhan hidup yang layak dari karyawan; 2) kinerja, sistem insentif dengan cara ini mengkaitkan besarnya insentif dengan kinerja yang telah ditunjukkan oleh pegawai yang bersangkutan; 3) lama karyawan bekerja, besarnya insentif ditentukan atas dasar lamanya karyawan melaksanakan atau menyelesaikan suatu pekerjaan.

Selanjutnya, 4) senioritas, sistem insentif ini didasarkan pada masa kerja atau senioritas karyawan yang bersangkutan dalam suatu organisasi; 5) keadilan dan kelayakan, dalam sistem insentif bukanlah harus sama rata tanpa pandang bulu, tetapi harus terkait pada hubungan antara pengorbanan (input) dengan (output). Makin tinggi pengorbanan, semakin tinggi pula insentif yang diharapkan, sehingga yang harus dinilai adalah pengorbanan yang diperlukan oleh suatu jabatan; 6) evaluasi jabatan, merupakan suatu usaha untuk menentukan dan membandingkan nilai suatu jabatan tertentu dengan nilai jabatan-jabatan lain dalam suatu organisasi. 


\section{Turnover Intention}

Turnover intention adalah kecenderungan niat karyawan untuk berhenti bekerja dari pekerjaannya secara sukarela menurut pilihannya sendiri. Turnover intention dipengaruhi oleh stres kerja dan lingkungan kerja berupa karakteristik individual dan faktor lingkungan kerja. Faktor individual meliputi umur, pendidikan serta status perkawinan. Adapun faktor lingkungan kerja adalah berupa hal-hal yang bersifat fisik dan nonfisik. Lingkungan kerja fisik meliputi keadaan suhu, cuaca, kontruksi, bangunan serta lokasi pekerjaan. Adapun lingkungan kerja nonfisik meliputi sosial budaya di lingkungan kerjanya, besar atau kecilnya beban kerja, kompensasi yang diterima, hubungan kerja seprofesi serta kualitas kehidupan kerjanya (Siregar, 2006).

Terjadinya turnover bisa saja disebabkan oleh berbagai faktor atau bisa jadi karena keinginan karyawan itu sendiri untuk berpindah ke perusahaan. Faktor-faktor yang mempengaruhi terjadinya turnover intention cukup kompleks dan saling berkait satu sama lain. Faktor-faktor tersebut antara lain adalah usia, lama kerja, tingkat pendidikan, keikatan terhadap organisasi, kepuasan kerja dan kebudayaan perusahaan (Nayaputera, 2011).

Menurut Mahdi et al., (2012) turnover intention terdiri atas 3 dimensi, yaitu sebagai berikut: 1) thinking of quitting (niat untuk keluar), yaitu pemikiran seseorang karyawan untuk keluar dari sebuah perusahaan dan adanya pemikiran bahwa ia berkemungkinan tidak bertahan dengan perusahaan tersebut; 2) intent to search (mencari pekerjaan), yaitu sikap seorang karyawan untuk mencari alternatif perusahaan lain; 3) intent to quit (memikirkan untuk keluar), yaitu sikap seorang karyawan yang menunjukkan indikasi keluar seperti meminimalisasi usaha dalam bekerja dan membatalkan pekerjaan penting.

\section{METODE PENELITIAN}

Penelitian ini dilaksanakan pada PT. Star Comgistic Indonesia Kabupaten Sukabumi dengan menggunakan metode kuantitatif. Analisis penelitian dilakukan secara deskriptif dan asosiatif. Sampel dipilih berdasarkan probabilitas sampling yang termasuk ke dalam simple random sampling dengan melakukan penyebaran kuesioner sebanyak 90 kepada karyawan PT. Star Comgistic Indonesia Kabupaten Sukabumi. Teknik analisa yang digunakan adalah teknik analisa uji validitas, uji reabilitas, analisis 
rergresi linear berganda termasuk uji koefisien determinasi dan koefisien korelasi ganda serta pengujian hipotesis menggunakan uji secara simultan (uji F).

\section{HASIL PENELITIAN}

\section{Uji Validitas}

Uji validitas adalah suatu taraf dimana alat pengukur dapat mengukur apa yang seharusnya diukur, sehingga suatu penelitian yang menggunakan kuesioner sebagian besar pengukurannya perlu di uji validitasnya. Biasanya syarat minimum untuk memenuhi syarat adalah kalau $r=0,3$. Jadi jika korelasi antara butir dengan skor total kurang dari 0,3 maka butir dengan instrumen dinyatakan tidak valid.

Pengujian validitas dilakukan menggunakan bantuan software SPSS 24 diperoleh sebagai berikut:

Tabel 2.

Hasil Uji Validitas

\begin{tabular}{ccccc}
\hline Variabel & Item & r-Hitung & r-Kritis & Keterangan \\
\hline \multirow{3}{*}{ Retensi Karyawan (X1) } & 1 & 0,379 & 0,3 & Valid \\
\cline { 2 - 5 } & 2 & 0,359 & 0,3 & Valid \\
\cline { 2 - 5 } & 3 & 0,367 & 0,3 & Valid \\
\cline { 2 - 5 } & 4 & 0,363 & 0,3 & Valid \\
\cline { 2 - 5 } & 5 & 0,367 & 0,3 & Valid \\
\cline { 2 - 5 } Insentif (X2) & 1 & 0,364 & 0,3 & Valid \\
\cline { 2 - 5 } & 2 & 0,366 & 0,3 & Valid \\
\cline { 2 - 5 } & 3 & 0,344 & 0,3 & Valid \\
\cline { 2 - 5 } & 4 & 0,3346 & 0,3 & Valid \\
\cline { 2 - 5 } Turnover Intention $(\mathrm{Y})$ & 5 & 0,337 & 0,3 & Valid \\
\cline { 2 - 5 } & 1 & 0,341 & 0,3 & Valid \\
\cline { 2 - 5 } & 2 & 0,238 & 0,3 & Valid
\end{tabular}

(Sumber: Data Primer (Kusioner), 2019)

Berdasarkan data tabel 2, dapat diketahui bahwa nilai korelasi antara skor item variabel retensi karyawan (X1), insentif (X2) dan turnover intention (Y) menunjukkan hasil pengujian dengan skor di atas 0,3, sehingga seluruh butir instrumen item variabel dinyatakan valid. 


\section{Uji Reabilitas}

Uji reliabilitas dilakukan dengan menggunakan rumus Cronbach's Alpha dengan bantuan SPSS 24 . Hasilnya adalah sebagai berikut:

Tabel 3.

Hasil Uji Reliabilitas

\begin{tabular}{cccc|}
\hline \multirow{2}{*}{ Variabel } & \multicolumn{2}{c|}{ Koefisien Cronbach's Alpha } & \multirow{2}{*}{ Keterangan } \\
\cline { 2 - 3 } & Hitung & Standar & Reliabel \\
\hline Retensi Karyawan (X1) & O, 716 & 0,6 & Reliabel \\
Insentif (X2) & O, 684 & 0.6 & Reliabel \\
Turnover Intention & 0,721 & 0,6 & \\
\hline
\end{tabular}

(Sumber: Data Primer (Kusioner), 2019)

Berdasarkan tabel 3 di atas, diperoleh hasil yang menunjukkan bahwa nilai $\alpha$ hitung > $\alpha$ standar $(0,6)$, sehingga dapat disimpulkan bahwa variabel-variabel yang dipakai dalam penelitian ini adalah reliabel. Dengan demikian, sangat jelas bahwa variabel-variabel tersebut dapat digunakan untuk penelitian selanjutnya karena dapat diandalkan.

\section{Koefisien Korelasi Ganda}

Tabel 4.

Hasil Uji Korelasi Ganda

\begin{tabular}{ccccc}
\hline \multicolumn{5}{c}{ Model Summary } \\
\hline Model & $\mathbf{R}$ & R Square & Adjusted $\mathbf{R}$ Square & Std. Error of the Estimate \\
\hline 1 &, $445^{\text {a }}$ &, 198 &, 180 & 1,033 \\
\hline a. Predictors: & (Constant), Insentif, Retensi Karyawan &
\end{tabular}
(Sumber: Data Primer (Kusioner), 2019)

Berdasarkan tabel 4 di atas, dapat diketahui bahwa angka $\mathrm{R}$ sebesar 0, 455 berada pada kategori 0,40 - 0,599. Hal ini menunjukkan bahwa terjadi hubungan yang sedang antara retensi karyawan dan insentif dengan turnover intention.

Koefisien Determinasi $\left(\mathbf{R}^{2}\right)$

Tabel 5.

Hasil Uji Koefisien Determinasi $\left(\mathbf{R}^{2}\right)$

\begin{tabular}{lcccc}
\hline \multicolumn{5}{c}{ Model Summary } \\
\hline Model & $\mathbf{R}$ & R Square & Adjusted $\mathbf{R}$ Square & Std. Error of the Estimate \\
\hline 1 &, $445^{\text {a }}$ &, 198 &, 180 & 1,033 \\
\hline a. Predictors: & (Constant), Insentif, Retensi Karyawan & \\
\hline
\end{tabular}


Berdasarkan data tabel 5, model summary menunjukkan besarnya adjusted $\mathrm{R}^{2}$ adalah sebesar 0,180. Hal ini berarti $18 \%$ variasi turnover intention dapat dijelaskan oleh dua variabel independen yaitu retensi karyawan dan insentif. Sedangkan sisanya $82 \%(100 \%-18 \%=82 \%)$ dipengaruhi dari faktor lain yang tidak diteliti dalam penelitian ini.

\section{Hasil Analisis Regresi Linear Berganda}

Tabel 6.

Hasil Analisis Regresi Linear Berganda

\begin{tabular}{|c|c|c|c|c|c|c|}
\hline \multicolumn{7}{|c|}{ Coefficients $^{a}$} \\
\hline & \multirow{2}{*}{ Model } & \multicolumn{2}{|c|}{ Unstandardized Coefficients } & \multirow{2}{*}{$\begin{array}{c}\text { Standardized Coefficients } \\
\text { Beta }\end{array}$} & \multirow{2}{*}{$\mathbf{t}$} & \multirow{2}{*}{ Sig. } \\
\hline & & $\mathbf{B}$ & Std. Error & & & \\
\hline \multirow{3}{*}{1} & (Constant) & 2,882 & 1,750 & & 1,647 & ,103 \\
\hline & Retensi Karyawan & ,069 & 078 & ,093 &, 885 & ,379 \\
\hline & Insentif & 277 &, 073 & ,399 & 3,784 &, 000 \\
\hline
\end{tabular}

(Sumber: Data Primer (Kusioner), 2019)

Berdasarkan ouput uji regresi linear berganda di atas, maka dapat diperoleh persamaan sebagai berikut:

$$
\mathrm{Y}=\mathbf{2 . 8 8 2}+\mathbf{0 , 0 6 9} \mathrm{X} 1+0,277 \mathrm{X} 2
$$

\section{Uji Signifkan Secara Simultan (Uji F)}

Tabel 7.

Hasil Uji F

\begin{tabular}{ccccccc}
\hline \multicolumn{8}{c}{ ANOVA $^{\text {a }}$} \\
\hline & Model & Sum of Squares & df & Mean Square & F & Sig. \\
\hline \multirow{2}{*}{1} & Regression & 22,930 & 2 & 11,465 & 10,741 &, $000^{\mathrm{b}}$ \\
& Residual & 92,859 & 87 & 1,067 & & \\
\hline \multicolumn{2}{c}{ Total } & 115,789 & 89 & & \\
\hline
\end{tabular}

a. Dependent Variable: Turnover Intention

b. Predictors: (Constant), Insentif, Retensi Karyawan

(Sumber: Data Primer (Kusioner), 2019)

Berdasarkan tabel 7 di atas, hasil uji F yang dilakukan menunjukkan nilai Sig. $0,000<0,05$; nilai $\mathrm{F}$ hitung $10,741>\mathrm{F}$ tabel 2,36 . Artinya bahwa retensi karyawan dan insentif berpengaruh positif dan signifikan terhadap turnover intention.

Hasil perhitungan analisis regresi berganda dengan uji $\mathrm{F}$ pada tingkat signifikan sebesar $10 \%(0,1)$ menunjukkan bahwa retensi karyawan dan insentif berpengaruh 
bersama-sama terhadap turnover intention, hal ini ditunjukkan dari hasil nilai Sig. 0,000 $<0,05$; nilai $\mathrm{F}_{\text {hitung }} 10,741>\mathrm{F}_{\text {tabel }} 2,36$.

\section{PEMBAHASAN}

Tenaga kerja atau sumber daya manusia merupakan faktor yang dapat mempengaruhi perkembangan perusahaan dan ikut berperan dalam menjalankan aktivitas perusahaan (Mustika, 2012). Kegagalan mengelola sumber daya manusia dapat menyebabkan timbulnya gangguan dalam pencapaian tujuan dalam organisasi, baik berupa kinerja, keuntungan maupun kelangsungan hidup organisasi tersebut (Rayadi, 2012). Permasalahan yang timbul ketika salah mengelola sumber daya manusia yaitu penurunan kinerja karyawan. Menurut Simamora (2004) kinerja merupakan kadar pencapaian tugas-tugas yang membentuk seluruh pekerjaan karyawan. Kinerja merefleksikan seberapa baik karyawan memenuhi persyaratan sebuah pekerjaan.

Keberhasilan perusahaan sangat tergantung bagaimana kinerja, efisiensi, kejujuran, ketekunan dan integritas karyawan (Ahmed \& Uddin, 2012). Terjadinya turnover yang tinggi pada suatu perusahaan atau organisasi dalam praktiknya dapat memberikan dampak negatif bagi koperasi. Keinginan karyawan untuk keluar dari perusahaan (turnover intention) tentunya akan menyulitkan bagian koperasi karena proses rekutmen yang telah berhasil merekrut staf yang berkualitas pada akhirnya ternyata menjadi sia-sia karena staf tersebut telah memilih pekerjaan di perusahaan yang lain (Sa'diyah et al., 2017).

Beberapa faktor yang mempengaruhi terjadinya turnover intention yaitu retensi karyawan dan pemberian insentif. Neog \& Barua (2015) menyatakan bahwa retensi karyawan merupakan kebijakan dan praktik yang digunakan organisasi untuk menghindarkan karyawan yang berharga keluar dari pekerjaan mereka. Adapun menurut Oyoo et al., (2016) retensi karyawan adalah sebuah proses dimana karyawan didorong untuk tetap tinggal di organisasi selama periode maksimum atau sampai selesainya proyek organisasi tersebut. Adapun kompensasi atau insentif adalah setiap bentuk pembayaran atau imbalan yang diberikan kepada karyawan dan timbul dari dipekerjakannya karyawan itu (Dessler, 2006).

Hasil penelitian menunjukkan bahwa retensi karyawan berpengaruh positif dan signifikan terhadap munculnya turnover intention pada diri karyawan. Hal ini 
berlawanan dengan hasil penelitian Sumarni (2011) yang menemukan bahwa tidak ada pengaruh secara signifikan antara retensi karyawan terhadap turnover intention. Namun, menurut Yurika (2011), retensi karyawan memiliki pengaruh terhadap munculnya turnover intention, dimana retensi karyawan akan meningkatkan efektifitas dan kinerja perusahaan karena dengan tingginya retensi, maka sudah pasti turnover akan menjadi rendah.

Hasil penelitian ini juga menunjukkan bahwa insentif berpengaruh positif dan signifikan terhadap munculnya turnover intention. Hal ini sejalan dengan hasil penelitian Pakaya (2015) yang menyatakan bahwa insentif memiliki pengaruh terhadap munculnya rasa turnover intention pada diri karyawan. Oleh karena itu, untuk mencegah terjadinya turnover intention, maka suatu organisasi atau perusahaan harus memperhatikan pemberian insentif bagi para karyawan sesuai dengan durasi lama kerja, beban kerja dan prestasi karyawan.

\section{SIMPULAN}

Berdasarkan hasil penelitian, maka dapat disimpulkan bahwa terjadi hubungan yang sedang antara retensi karyawan dan insentif dengan turnover intention. Retensi karyawan dan insentif berpengaruh positif dan signifikan terhadap turnover intention. Hal ini menunjukkan bahwa retensi karyawan dan insentif merupakan faktor yang membentuk turnover intention pada PT. Star Comgistic Indonesia Kabupaten Sukabumi.

\section{DAFTAR PUSTAKA}

Ahmed, S., \& Uddin, M. N. (2012). Job Satisfaction of Bankers and Its Impact in Banking: A Case Study of Janata Bank. Journal ASA University Review, 6(2), 96-97

Carsen, J. A. (2005). HR How to Employee Retention. Chicago: J.D. CCH Incorporated Dessler, G. (2006). Manajemen Sumber Daya Manusia. Jakarta: PT. Indeks

Hasibuan, M. S. P. (2011). Manajemen Sumber Daya Manusia, Edisi Revisi. Jakarta: PT. Bumi Aksara

Mahdi, A. F., Zin, M. Z. M., Sakat, A. A. (2012). The Relationship Between Job Satisfaction and Turnover Intention. American Journal of Applied Sciences, 9(9), 1518-1526

Mangkunegara, A. P. (2008). Manajemen Sumber Daya Manusia Perusahaan. Bandung: Rosda 
Mangkunegara, A. P. (2009). Evaluasi Kinerja Sumber Daya Manusia. Bandung: Refika Aditama

Mathis, R. L., \& Jackson, J. H. (2006). Human Resource Management: Manajemen Sumber Daya Manusia, Diterjemahkan: Angelia, D. Jakarta: Salemba Empat

Mobley, R. K. (2002). An Introduction to Predictive Maintenance, 2nd Edition. USA: Butterworth-Heinemann

Mustika, I. K. (2012). Analisis Budaya Organisasi dan Kepuasan Kerja Melalui Komitmen Pengaruhnya terhadap Intent to Leave Karyawan pada Industri Jasa Perhotelan di Kabupaten Badung dan Kota Denpasar. Jurnal Mitra Ekonomi dan Manajemen Bisnis, 3(1), 1-24

Nawawi, H. (2008). Manajemen Sumber Daya Manusia untuk Bisnis Kompetitif. Yogyakarta: Gadjah Mada University Press

Nayaputera, Y. (2011). Analisis Pengaruh Kepuasan Kerja dan Stres Kerja terhadap Intensi Turnover Customer Service Employee di PT. Plaza Indonesia Realty Tbk. Tesis. Universitas Indonesia

Neog, B. B., \& Barua, M. (2015). Factors Affecting Employee's Retention in Automobile Service Workshops of Assam: An Empirical Study. The SIJ Transactions on Industrial, Financial \& Business Management, 3(1), 9-18

Oyoo, M. O., Mwandihi, N. K., \& Musiega, D. (2016). Influence of Reward Systems on Employee Retention in Faith Based Health Organizations in Kenya : A Case of Mukumu Hospital, Kenya. International Journal of Commerce and Management Research, 2(10), 42-51

Pakaya, H. A. (2015). Pengaruh Insentif terhadap Intention Turnover Perawatan di RSUD Otahana Kota Gorontalo. Skripsi. Universitas Negeri Gorontalo

Rayadi, R. (2012). Faktor Sumber Daya Manusia yang Meningkatkan Kinerja Karyawan dan Perusahaan di Kalimantan Barat. Jurnal EKSOS, 8(2), 114-119

Rivai, V. (2009). Manajemen Sumber Daya Manusia untuk Perusahaan dari Teori ke Praktik. Jakarta: Raja Grafindo Persada

Sa'diyah, H., Irawati, S. S., \& Faidal, F. (2017). Pengaruh Employee Retention dan Turnover Intention terhadap Kinerja Karyawan Melalui Kepuasan Kerja pada Kospin Jasa Cabang Jawa Timur. Kompetensi, 11(1), 34-65

Simamora, H. (2004). Manajemen Sumber Daya Manusia, Edisi Ketiga. Yogyakarta: STIE YKPN

Siregar, A. H. (2006). Pengaruh Kepuasan Kerja terhadap Intensi Turnover Karyawan Produksi pada PT. Riau Crumb Rubber Factory. Skripsi. Universitas Sumatera Utara Medan

Sumarni, M. (2011). Pengaruh Employee Retention terhadap Turnover Intention dan Kinerja Karyawan. Akmenika UPY, 8, 20-47

Yurika, Y. (2011). Analisis Manajemen Karir, Lingkungan Kerja dan Kpepuasan Kerja terhadap Retensi Karyawan Serta Dampaknya terhadap Kinerja Perusahaan pada PT. Origa Mulia FRP. Skripsi. Universitas Bina Nusantara Jakarta 